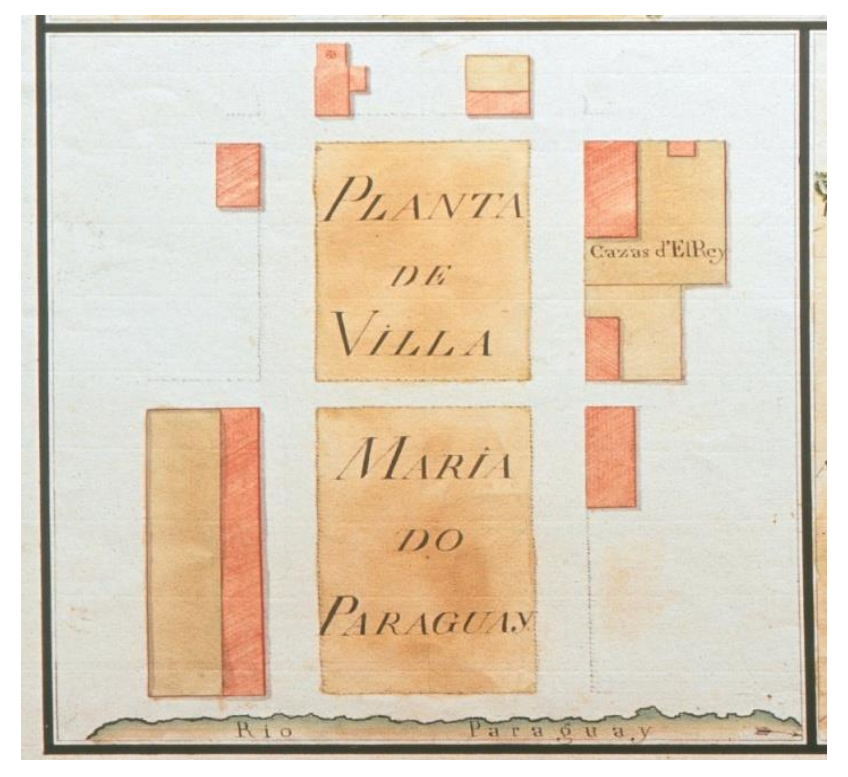

\title{
Cáceres - nome luso de cidade mato-grossense
}

Cáceres - portuguese name of mato-grossense city

Neuza Zattar ${ }^{1}$

\section{Resumo:}

Vários foram os nomes dados à Villa Maria do Paraguay (1778) até a sua transformação em cidade nomeada como Cáceres (1938) em acontecimentos do dizer perpassados pela história e pela memória luso-brasileira. Neste artigo, desenvolvido na perspectiva da Semântica do Acontecimento, tomamos os nomes próprios de vila e cidade como uma construção linguística e histórica exposta à exterioridade, cujos sentidos se alteram, dispersam e também se mantêm. Em relação à legislação urbana, observamos que exceto a ata de fundação que institui um plano de edificação para a vila, os Códigos de Postura (1860, $1876,1948)$ funcionam como o interpretável do que se diz em relação a um passado de enunciações em que os nomes foram se dando.

Palavras-chave: Semântica do Acontecimento; Nome próprio, Nomeação; Vila; cidade.

\section{Abstract}

Several names have been given to Villa Maria do Paraguay (1778) until its transformation in the city named as Caceres (1938) in speaking events by the history and luso-brazilian memory. In this article, developed in the context of the Semantics of the Event, we take the proper names of village and town as a linguistic and historical construction exposed to the externality, whose meanings change, disperse and also remain themselves. Regarding the urban legislation, we observed that except the minutes of the founding that establishes a plan for building for the village, the Codes of Posture $(1860,1876,1948)$ work as the interpretable of what they say in relation to a past of utterances in which the names were getting throughout the time.

Keywords: Semantics of the Event. Proper names; Nomination; Village; City.

\footnotetext{
${ }^{1}$ Professora do Departamento de Letras e do Programa de Mestrado em Linguística da Universidade do Estado de Mato Grosso -UNEMAT/Cáceres. Universidade do Estado de Mato Grosso, Departamento de Letras, Campus de Cáceres. Av. São João s/n. Cavalhada 78200-000 - Caceres, MT - Brasil. E-mail: neuza.zattar@gmail.com
} 
A política de criação e povoação de vilas no Brasil foi instituída no reinado de D. Pedro II (1667-1706), continuou com D. João V (1706-1750) e se manteve com D. José I (1750-1777), através de Cartas Régias e Instruções encaminhadas ao Vice-Rei do Brasil, para que as autoridades de todas as regiões fundassem vilas "naquelas que fossem mais convenientes e que a elas se congregassem todos os vadios e dispersos ou que vivem em sítios volantes, para morar em povoações civis"2.

Garantida a política de ocupação de espaços brasileiros pelo processo de criação de vilas ao longo da costa litorânea, a Coroa portuguesa volta, então, os olhos para o interior - o sertão desconhecido -, no sentido de explorar terras, demarcar fronteiras oeste com os espanhóis, fundar vilas e incorporá-las ao seu controle administrativo e fiscal.

Os primeiros povoados no Brasil foram batizados de vilas e no território matogrossense, na segunda metade do século XVIII, não foi diferente, com a fundação da Villa Maria do Paraguay (1778), no caminho entre Vila Real do Bom Jesus do Cuiabá (1719), a atual capital, e Vila Bela da Santíssima Trindade (1752), a primeira capital de Mato Grosso, por ordem do Governador da Capitania de Mato Grosso, Luís de Albuquerque de Mello Pereira e Cáceres, em 6 de outubro de 1778, que resultaria "em grande utilidade ao real serviço e commodidade publica" pela estratégica localização de um registro ${ }^{3}$ e de reforço defensivo da capital e de Cuiabá contra os espanhóis.

Neste texto, sob o viés da Semântica do Acontecimento, propomos analisar o nome "Villa Maria do Paraguay" dado ao povoado na ata de sua fundação e outros nomes que se seguiram até a sua constituição em cidade, bem como a relação semântico-enunciativa entre o espaço público nomeado e a configuração desse espaço em relação à legislação.

A seguir, reproduzimos a primeira parte da ata documental que dá existência jurídico-administrativa ao povoado:

Anno do Nascimento de Nosso Senhor Jesus Christo de 1778, aos 6 dias do mez de outubro do dito anno, n'este districto do rio Paraguay e margem oriental d'elle, no lugar onde presentemente se dirige a estrada que se seguia à Cuyabá desde Villa Bella, sendo presente o Tenente de Dragões Antonio Pinto do Rego e Carvalho, por elle foi dito que tinha passado a este dito lugar por ordem do Ilmo. e Exm. Snr. Luís de Albuquerque de Mello Pereira e Cáceres, Governador e Capitão General d'esta Capitania de Mato Grosso, para com effeito fundar, erigir e consolidar uma

\footnotetext{
${ }^{2}$ Cf. trecho da carta do Conde de Oeiras, in Maria Fernanda Derndt, 2010, p. 01.

${ }^{3}$ Cf. Renata Araujo (2001, s/p), o governador Albuquerque "fez instalar nas proximidades do marco do Jauru um posto de Registro, com destacamento militar permanente. O Registro do Jauru foi instalado na estrada que ligava Vila Bela a Cuiabá. A sua principal função era, supostamente, controlar o eventual desvio de ouro que alguns contrabandistas poderiam estar a fazer".
} 
povoação civilizada, aonde se congregassem todo o maior número de moradores possível, comprehendidos todos os casaes de índios castelhanos proximadamente desertados para estes Domínios Portuguezes da Província de Chiquitos, que fazem o número de 78 individuos de ambos os sexos, a que juntando-se todo o outro numero das mais pessoas congregadas para o dito fim faz o total de 161 individuos de ambos os sexos; cuja povoação, segundo as ordens do dito, se denominará de hoje em diante, em obsequio do real nome de Sua Majestade - Villa Maria do Paraguay, - esperando-se que de semelhante estabelecimento haja de resultar grande utilidade ao real serviço e commodidade publica [...].

Inicialmente, faremos uma abordagem sobre as vilas ${ }^{4}$ no Brasil, tendo em vista o emprego desse topônimo, na enunciação dos Governadores portugueses, para nomear sítio, povoado, arraial, lugarejo, aldeamento recém-criados e/ou fundados no período da colonização no Brasil. Para os portugueses, salpicar o chão do Brasil com vilas significava, além da garantia de maiores lucros do comércio real, a primazia sobre outros conquistadores na ocupação territorial da colônia em vários pontos do país.

A vila se instituía por ata, um instrumento jurídico que lhe dava autonomia e poder político-administrativo sobre o espaço e as pessoas que nela viviam. A vila, segundo Moraes (1789), era uma "povoação de menor graduação que a Cidade, e superior a aldeia, tem juiz, camara, e pellourinho", e por essa acepção, a vila e a população seriam assujeitadas pelas autoridades locais que, por sua vez, seriam reguladas pelas políticas do Estado português no Brasil.

Em Mato Grosso, na segunda metade do século XVIII, conforme Araujo5, “o processo de incorporação progressiva do território sustentou-se sobre o estabelecimento de um suporte jurídico-institucional, no qual a vila ocupa um papel preponderante [...]", a vila significava a ocupação política do território, e com a instalação de câmaras coloniais, os habitantes passam a estabelecer uma relação jurídica direta com as autoridades locais e indiretamente com o Estado português, construindo, assim, o início das relações históricas, políticas e de dominação entre povoados e povoadores e da instalação da memória lusa no território mato-grossense.

\footnotetext{
${ }^{4}$ Cf. Beatriz Piccolotto S. Bueno (2003, p. 435 apud MARIA FERNANDA DERNDT, 2010, p. 34), estima-se que, até o fim do reinado de D. Pedro II (1667-1706), tenham sido criadas cinquenta vilas; já sob D. João V (1706-1750), foram trinta e uma elevações e, durante o reinado de D. José I (1750-1777), sessenta 60 novas vilas, voltando a decrescer entre 1777 e 1808, com 35 vilas. O investimento na criação de cidades foi sempre muito menor: apenas nove entre 1500 e 1750; e mais uma cidade (Oeiras, PI, 1758), até 1808.

${ }^{5}$ Cf. Renata Malcher de Araujo. In: "A urbanização da Amazónia e do Mato Grosso no século XVIII povoações civis, decorosas e úteis para o bem comum da coroa e dos povos".

Disponível em: http://www.scielo.br/scielo.php?pid=S0101-47142012000100003\&script=sci_arttext Acesso em: 7/01/2014.
} 


\section{O nome do povoado}

Nomear um povoado é um acontecimento do dizer que faz diferença na sua própria ordem. O gesto de nomear sob a ordem do Governador uma localidade 'sem nome' significa, na enunciação do colonizador, a legitimação da posse, a transposição do rural para o urbano e a instalação de um nome na história luso-brasileira.

A nomeação, segundo Guimarães (2005b, p.9), "é o funcionamento semântico pelo qual algo recebe um nome". Nomear, dar nome a alguém, se dá no acontecimento de linguagem, pelo funcionamento da língua, por entendermos que a língua funciona afetada pelo interdiscurso, pela exterioridade a que está exposta.

O nome próprio do povoado, que trataremos aqui, se dá no acontecimento do dizer em relação com os sujeitos falantes, ou melhor, em relação com a linguagem, com a exterioridade e com o sujeito, por compreender que "o dizer constitui-se como acontecimento na relação entre uma demanda do presente desse acontecimento e memoráveis de outros enunciados" (DIAS, 20136).

Nessa perspectiva, o nome próprio se constitui linguístico-historicamente, identificando e/ou classificando social e juridicamente pessoas, povoados e objetos, pois o acontecimento de nomear se dá pelo cruzamento de diferentes lugares enunciativos que levam à nomeação do povoado, como o lugar social do Governador Albuquerque, designado pela rainha D. Maria I para explorar e tomar posse de terras na América portuguesa, e do Tenente de Dragões Antonio Pinto do Rego e Carvalho que, sob a ordem do Governador, funda a Villa.

A nomeação do povoado "Villa Maria do Paraguay", conforme a ata, deu-se "em obsequio do real nome de Sua Majestade", D. Maria I, por ordem do Governador da Capitania de Mato Grosso, no entanto, a ata não textualiza o significado do sintagma preposicional "do Paraguai" na construção desse nome. Se suprimirmos o topônimo "Villa", obteremos o nome "Maria do Paraguay", em que o sintagma "do Paraguay", por analogia, predicaria "Maria", atribuindo-lhe uma especificidade de origem que não é o caso, pois o nome da rainha Maria está ligado à Corte de Portugal e não ao rio que banha a vila. Mas, então, por que relacionar esse sintagma ao nome de "Maria"?

É possível dizer que o lugar social do Governador Albuquerque relaciona-se com uma história de enunciações que vai determinando o nome. O nome "Paraguay" rememora as enunciações do relato de viagem do Governador que assim descreve o rio:

\footnotetext{
${ }^{6}$ Cf. Conferência apresentada no VII ENALIHC/UNEMAT, em Cáceres-MT, em 20/09/2013.
} 
"[...] dipois de passado em canoa o rio Paraguay, que hé bastantemente largo naquele sitio" $[\ldots]^{7}$. Esse nome é retomado na ata de fundação "n'este districto do rio Paraguay e margem oriental d'elle", de modo que enunciar o nome da vila não evoca apenas a rainha de Portugal, mas também o rio existente e já nomeado, que projeta uma identidade geográfica ao local demarcado pelo domínio português.

Para compreendermos a estrutura morfossintática do nome "Maria do Paraguay (nome próprio seguido de um sintagma preposicionado), vamos tomar os sintagmas:

b) Villa Maria;

a) Villa do Paraguay.

Em (a), o nome próprio "Maria” refere a monarca de Portugal, nome memorável que significa também pela devoção religiosa da Corte com a Igreja católica; e em (b), o sintagma faz referência ao rio que banha a margem esquerda da vila. Pelas paráfrases, o sintagma "do Paraguay" não predica "Maria", como nos leva a pensar a priori, mas sim a "Villa" pela relação do rio com os habitantes, característica local que dá à nomeação uma relação metonímica e de pertencimento do rio à vila e vice-versa.

Conforme Kehdi (2007, p.35), no nome composto, "os elementos que o constituem perdem a significação própria em benefício de um único conceito, novo, global”. Essa relação, porém, não ocorre no funcionamento semântico-enunciativo do nome da "Villa, em que os elementos que o formam têm a sua própria história e se juntam para instituir uma nova história de sentidos pela qual a vila passa a significar.

No enunciado “o Tenente de Dragões Antonio Pinto do Rego e Carvalho [...] tinha passado a este dito lugar por ordem do Governador [...] para com effeito fundar, erigir e consolidar uma povoação civilizada", o "dito lugar" rediz o já dito no diário de viagem do Governador durante a sua vinda do Rio de Janeiro para a Capitania de Mato Grosso, em 1772:

[...] O Rio Paraguay que aqui corre já hé bastantemente grande; acha-se aqui situado hum registro aonde rezide hum piqueno destacamento, há fazenda de gado bastantemente povoada; poucas legoas abaixo deste sitio faz este rio confluencia com o do Jaurú, e neste lugar se acha posto o marco que devia servir as demarcaçoens. ${ }^{8}$ (grifo nosso)

\footnotetext{
${ }^{7}$ Cf. Diário (Ao 103. ${ }^{\circ}$ dia de viagem) de Luiz de Albuquerque na viagem do Rio de Janeiro à Capitania de Mato Grosso (1772), in Freyre (1978, p. 281).

${ }^{8}$ Cf. Diário (Ao 102. ${ }^{\circ}$ dia de viagem) de Luiz de Albuquerque na viagem do Rio de Janeiro à Capitania de Mato Grosso (1772), in Freyre (Idem).
} 
Nesse trecho do diário, a vila é instalada numa povoação pré-existente, descrita pelo olhar do colonizador como uma gravura bucólica na qual aparece em primeiro plano um rio grande e, à sua margem esquerda, um povoado contendo um registro (posto fiscal) habitado por um pequeno aparelhamento militar e uma fazenda de gado povoada; em segundo plano, o marco de Jauru, símbolo de demarcação na fronteira com os domínios espanhóis. Essas propriedades, na visão do Governador, davam ao "sitio" condições para nomeá-lo e incorporá-lo jurídica e administrativamente à Coroa, de modo a transformar o espaço rural em "povoação civilizada".

O modo de olhar do sujeito colonizador estabelece relação com o que diz Berger (1999, p. 11), em Modos de Ver:

Nunca olhamos para uma coisa apenas; estamos sempre olhando para a relação entre as coisas e nós mesmos. Nossa visão está continuamente ativa, continuamente em movimento, continuamente captando coisas num círculo à sua própria volta, constituindo aquilo presente para nós do modo como estamos situados.

Ou seja, há uma determinação política que afeta o modo de ver o "sítio" sob vários ângulos, e nesses modos de ver "o sujeito ao significar se significa, e esse gesto é necessário por ligar língua e história na produção dos sentidos" (ORLANDI, 1996, p. 22).

Retomando a ata de fundação, os verbos no enunciado "fundar, erigir e consolidar uma povoação civilizada" significam uma ruptura com o sítio sem dono agora institucionalizado, constituindo um confronto entre o passado e o presente, o atraso e o progresso, o rural e a vila, a terra sem lei e a terra administrada que, no caso, transformaria os "casaes de índios castelhanos [...]" e "todo o outro numero das mais pessoas congregadas" em indivíduos sociáveis.

Queremos destacar o emprego da forma "civilizada" e não de "civilização" na relação dos fundadores com a população local. Sobre a diferença entre essas duas palavras, Benveniste (1995), no estudo sobre a gênese da palavra civilização na cultura moderna, mostra essa diferença formulada por Boswell, para quem civility significa "civilidade, polidez", e civilization, o contrário de "barbárie" (p. 377). A forma empregada na ata significa, por um pré-construído, que os índios habitantes da vila não eram selvagens e/ou bárbaros, e já haviam sido catequizados pelas missões espanholas, mas que, com o novo ordenamento espacial, precisavam de certa polidez para o novo convívio e as mudanças que iriam afetar os sujeitos e os dizeres. 
Ainda, no trecho do diário, as formas dêiticas "aqui", "deste sitio" e "neste lugar", além de fazer referência ou apontar o "sitio", o extralinguístico, reafirmam, no diário de viagem do Governador, a aprovação política e geográfica do lugar para as finalidades de posse e povoação.

\section{O desenho do espaço conquistado}

Neste item apresentamos a segunda parte da ata, que institui a escrita do projeto de edificação da Vila.

[...] e porque supposto o plano do terreno para a dita Villa se acha com alguma disposição para continuar a fundar-se com regularidade; comtudo, como alguns dos alinhamentos não estão conformes ao projecto da boa policia, como deveria ser, determinou elle, dito Tenente, a todos os moradores, em nome de S. Ex., que deixando de fazer mais algum beneficio a varias cabanas existentes, só n'ellas assistem em quanto se fabricavam casas no novo arruamento, que lhe fica prescrito e balisado por elle, Tenente, com marcos sólidos de páo de lei, sendo obrigados a não excederem nem diminuírem a dita construção na altura de 14 palmos de pé direito na frente de todas as casas as que se levantarem e 24 palmos de altura no cume; outrossim, determinou que precisamente chamariam para regular os ditos pés direitos ao carpinteiro João Martins Dias, e na falta d'este outro algum inteligente no officio, afim de conservar sem discrepancia, segundo o risco, a largura de 60 palmos de ruas que estão assignadas por elle, dito Tenente; cujas actualmente demarcadas e abalisadas terão os seguintes nome, a saber: a primeira, contando do norte, rua d'Albuquerque, a immediata, para o sul, rua de Mello, as quais ambas vão desembocar na praça e cada uma d'ellas faz face a mesma do norte e do sul, assim como também as travessas de 30 palmos, que dividem os quartéis das ditas ruas, e se denominarão estas travessas, a primeira, contando do poente para o nascente, travessa do Pinto, e a que se segue, contando também para o nascente, travessa do Rego, e no alto da praça da mesma banda do nascente cuja frente fica riscada entre as ruas e travessas ditas com 360 palmos cujo número tem também as mais quadras, poderão os moradores erigir a sua igreja por ficar a porta principal d'ella para $o$ poente, como o determinam os rituaes; e o mais terreno d'esta frente da praça por agora se não ocuparia em casas, deixando-o livre para as do conselho e cadeia quando se deverem fabricar. Cada morada dos ditos povoadores não terá mais de 100 palmos de comprimento para quintal, que lhes ficam determinados para o centro de cada um dos quartéis. $\mathrm{O}$ que tudo assim executado pelo dito Tenente de Dragões na presença de todos os moradores, mandou a mim, Domingos Ferreira da Costa, Fiel d'este registro, que serviu de escrivão, fizesse esse termo para constar do referido, o qual assignou com as testemunhas seguintes [...] (MENDES, 2009, p. 2729). (grifo nosso)

Nesse trecho, a ata de fundação organiza textualmente a espacialidade da Vila, sob a lente do colonizador, demarcando os espaços, a partir dos ordenamentos previstos 
no "projecto da boa policia" (ZATTAR, 2011), cujas formas encontram-se simetricamente ligadas entre si, como mostra a planta abaixo.

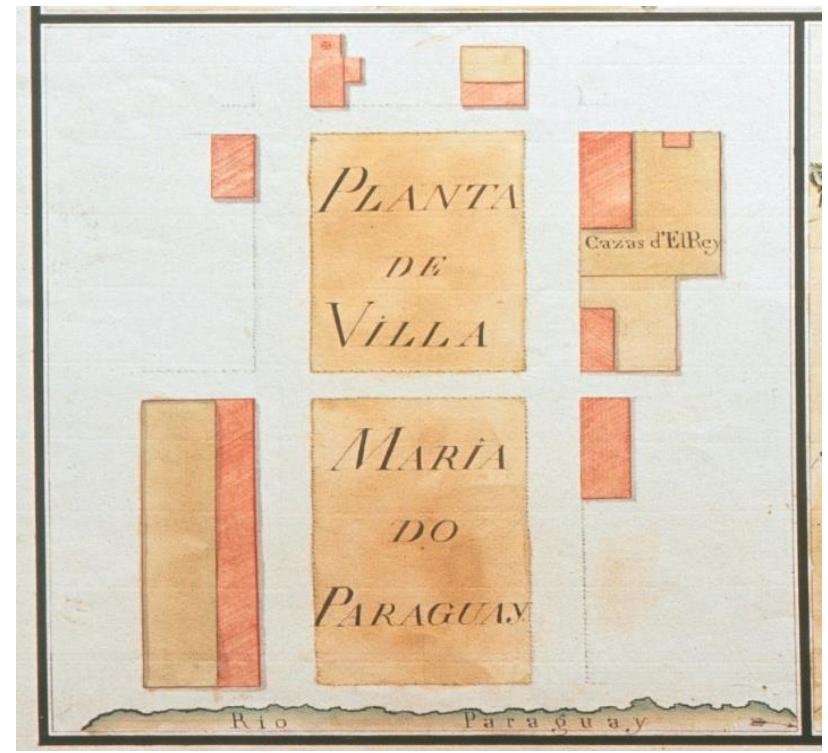

colecao-imagens-periodo-colonial-mato-grosso/678/ Disponível em http://www.sudoestesp.com.br/file/

$\mathrm{O}$ acontecimento da ata, que projeta o planejamento dos espaços da vila, funda uma memória de sentidos ao instituir o novo, a edificação de casas, ruas, e a instalação de instituições indispensáveis ao funcionamento da Vila, pela sobreposição dos sentidos anteriormente constituídos e estabilizados, que se marca na passagem do sítio para vila:

1) O sítio (o rural) como passado: a substituição das "várias cabanas existentes" por "casas" constitui o memorável na enunciação do novo, e, ao mesmo tempo, institui novos lugares sociais para os sujeitos rurais, que passarão a estabelecer uma relação de individuação fundante com as instituições a serem instaladas: Igreja (a religião católica), conselho (o jurídico), cadeia (a punição), quartéis (a segurança da vila).

2) A vila como presente - a construção de "casas no novo arruamento", tipo de madeira, precisão das medidas, alinhamento, localização das ruas e travessas com as respectivas denominações, os lugares indicados para a edificação da praça, quartéis, igreja, quadras, conselho e cadeia, quintais, formando um mosaico linguístico e histórico, que constitui novas referências para a localidade e para os sujeitos.

As novas formas no espaço da vila - casa, rua d'Albuquerque, rua do Mello, travessa do Pinto, travessa do Rego, praça, quartéis, quadras, igreja, conselho e cadeia, constituem "o enunciável (o dizível) [...]" que "se apresenta como séries de 
formulações distintas e dispersas que formam em seu conjunto o domínio da memória" (ORLANDI, 1992, p. 90 in GUIMARÃES, 2005a, p. 66).

Na descrição da planta da Vila, as vozes do "Tenente" e do "escrivão" se dão simultaneamente, na medida em que o "Tenente" explica a edificação da Vila, o escrivão vai lavrando a ata, dando corporeidade à linguagem técnica de construção militar e à constituição da imagem do "Tenente" como desenhista responsável pelo projeto, sob a ordem do Governador. Ou seja, um modo de construção da linguagem que "funciona como um conjunto de regularidades, socialmente construídas, que se cruzam e podem ir permitindo mudanças nos fatos sem que isso possa ser visto como desvio ou quebra de uma regra (GUIMARÃES, 2002, p. 17).

Vamos aos recortes:

a) "como alguns dos alinhamentos não estão conformes ao projecto da boa polícia, como deveria ser, determinou elle, dito Tenente, a todos os moradores, em nome de S. Ex.[...]"; (grifo nosso)

b) "em quanto se fabricavam casas no novo arruamento, que lhe fica prescrito e balisado por elle, Tenente, [...]”; (grifo nosso)

c) determinou que precisamente chamariam para regular os ditos pés direitos ao carpinteiro João Martins Dias, e na falta d'este outro algum inteligente no officio, afim de conservar sem discrepancia, segundo o risco, a largura de 60 palmos de ruas que estão assignadas por elle, dito Tenente [...]"; (grifo nosso)

d) O que tudo assim executado pelo dito Tenente de Dragões na presença de todos os moradores, [...]”. (grifo nosso)

No aspecto da normatização, a ata de fundação funciona como um código de posturas que disciplina a ocupação do território, estabelecendo lugares para a edificação das casas, instituições e espaços públicos. Os sentidos de edificação do território ocupado se movimentam, significando que os limites preliminarmente definidos na planta serão irrompidos pela ocupação dos lugares não previstos no projeto de edificação.

A repetição da forma "Tenente" nas expressões "dito Tenente", "elle, Tenente", “elle, dito Tenente" produz o efeito do já dito da identificação da autoridade pela patente militar e de seu lugar social de co-fundador determinado pelas ordens do Governador.

$\mathrm{Na}$ expressão "O que tudo assim executado pelo dito Tenente" (item "d"), o pronome indefinido "tudo" condensa todo o texto da ata de fundação da Vila, reescriturando "o que já foi dito, fazendo interpretar uma forma diferente de si" 
(GUIMARÃES, 2007, p. 84). Esse procedimento de deriva de sentidos, segundo o autor, "atribui (predica) algo ao escriturado" (Idem).

\section{De Villa Maria a Cáceres}

Neste item queremos examinar a relação semântico-enunciativa entre o espaço público nomeado (vila, cidade) e a configuração desse espaço em relação à legislação, observando se a lei, que organiza, delimita e define os espaços públicos, é que determina social e historicamente o acontecimento do dizer que nomeia esse espaço na passagem/mudança da condição de vila para cidade.

Em carta ${ }^{9}$ dirigida a Martinho de Mello e Castro ${ }^{10}$, em dezembro de 1779 , o Governador da Capitania de Mato Grosso relata as melhorias da Vila Maria e da necessidade de se criar uma paróquia já solicitada ao vigário da Igreja e da Vara de Cuiabá "a constituírem o Distrito de Nova Freguesia de Vila Maria".

O capelão José Correa Leitão em correspondência ao Governador Albuquerque, no mesmo ano, sugere o nome da freguesia, dizendo:

Assim como a Vila tem o título de Maria, também a igreja há de ter o seu. E apressa com queeu [...] de fazer a coisa me tirasse o tempo de consultar = eu para perpetuar na daquela Vila o nome de V. $\mathbf{E x}^{\mathrm{a}}$ poria o seguinte = Freguesia de São Luiz de Vila Maria de Paraguai $=$ V. Ex ${ }^{\mathrm{a}}$ me determinará o que hei de obrar ${ }^{11}$. (Grifo nosso)

Um ano depois (1780), o bispo D. José Joaquim J. Mascarenhas cria a freguesia de "São Luiz da Villa Maria do Paraguai", retomando o já dito no documento formulado pelo Capelão e não no documento do Governador que sugere o nome "Distrito de Nova Freguesia de Vila Maria". O estabelecimento dos sentidos de um nome e não de outro relaciona-se ao interpretável do que se diz a partir de um memorável que significa, e a renomeação "São Luiz da Vila Maria do Paraguai” passa a significar o estreitamento das relações de poder entre o Governador e os religiosos da prelazia de Cuiabá (Bispo e capelão), que se fundem por interesses do país que representam no território colonizado e pelas missões que lhes foram determinadas.

Essa renomeação do lugar da Igreja católica significa a elevação da Vila à condição de freguesia pela instalação da Igreja que, além da doutrinação da religião

\footnotetext{
${ }^{9}$ Cf. carta in Fundação de Vila Maria, homenagem da UFMT aos 200 anos da cidade de Cáceres, 1978.

${ }^{10}$ Secretário de Estado dos Negócios da Marinha e Ultramar, à época do reinado de D. María.

${ }^{11}$ Cf. carta in dissertação A Igreja Católica na Cuiabá Colonial: da primeira Capela à chegada do primeiro Bispo (1722 - 1808), de Klebar Roberto Lopes Corbalan, UFMT, 2006.

Disponível em

http://www.ppghis.com/dissertacao/arquivos/Diss_Kleber_Corbalan_PPGHis_UFMT.pdf

Acesso em: 16/03/2014.
} 
católica, passa a regular a população por meio de registros de nascimento, casamento e óbito, da catequese dos nativos, segundo Hoornaert (1977 apud CORBALAN, 2006), entre outras formas de individuação do sujeito às normas da Igreja.

$\mathrm{Na}$ textualidade do recorte formulado pelo capelão, a escolha do prenome do Governador na composição do nome da freguesia "São Luiz da Vila Maria do Paraguai", não só o compara com a autoridade da rainha D. Maria como the confere ar de santidade, conforme o enunciado: "Assim como a Vila tem o título de Maria, também a igreja há de ter o seu."

O nome "São Luiz", ao contrário do que circula na linguagem dos católicos da cidade de Cáceres, não está associado a São Luíz (santo) ou Luíz XI, rei da França, mas curiosamente ao Governador Luiz de Albuquerque.

Chamam a atenção, no enunciado "eu para perpetuar na daquela Vila o nome de V. Ex ${ }^{\text {a }}$ poria o seguinte = Freguesia de São Luiz de Vila Maria de Paraguai”, os gestos de deferência do capelão e de anuência do Governador na indicação de seu nome, que embora se signifiquem de modos distintos, reafirmam a política de ocupação e nomeação de terras brasileiras pela Corte portuguesa.

Podemos perceber que os gestos de nomear vila, instituição religiosa e espaços públicos com nomes dos próprios colonizadores, a exemplo das ruas d'Albuquerque e de Mello (nome do fundador) e das travessas do Pinto e do Rego (nome do co-fundador) na ata de fundação, rememoram os modos da presença da colonização portuguesa, construindo uma rede de sentidos cujos fios se juntam para construir as histórias do país, e instalam, na posse institucional da Vila Maria, a marca nominal do Estado português pelo nome do fundador, significando terra pertencente a, "Submetida. Assim como seus habitantes" (ORLANDI, 2011, p. 108).

Hércules Florence (1977, p.199), desenhista da expedição do cônsul Langsdorf, ao chegar à Vila Maria em 1827, assim descreve a condição da vila:

Do mesmo modo que os outros povoados de Mato Grosso, não merece este a qualificação de vila. Um renque de casas em mau estado, de cada lado de uma grande praça, uma igrejinha sob a invocação de São Luis de França, muros de separação por trás das casas, eis tudo. (grifo nosso)

Decorrido quase meio século da visita de Florence, a "Freguesia de São Luiz de Vila Maria do Paraguai" foi elevada à vila com o nome de "São Luiz do Paraguai", pela Lei Provincial n. ${ }^{\circ}$, de 1850 . Na renomeação da vila, dada do lugar políticoadministrativo do governo provincial de Mato Grosso, observa-se que na nova elevação, 
a vila alcançou a condição deste topônimo dado na ata de sua fundação. A renomeação é determinada pelas políticas provinciais e, alcançar essa denominação nos faz pressupor que o interpretável do projeto de edificação e de instalação dos órgãos públicos ditos na ata se efetivou um século depois da fundação da vila. Em relação ao nome "São Luiz do Paraguai”, mantém-se o nome do santo por evocação ao nome do Governador, seguido do sintagma preposicionado "do Paraguai". Aqui o nome da rainha cessa de produzir os seus efeitos, e o sintagma "do Paraguai", que se mantém no nome oficial, também não predica o nome "São Luiz". Trata-se de dois nomes que têm histórias diferentes e que se unem para compor novas histórias entre o nome já existente - Rio Paraguai - e o nome que veio de fora, do lusitano "Luis".

A partir dessa condição, outros mecanismos para organização espacial da vila surgem com o loteamento dos espaços públicos e a aquisição de lotes, através do chamado Código de Posturas que, instituído em 1860, traça o planejamento do espaço da vila, normatiza a edificação de prédios particulares, estabelecendo as primeiras relações de compra e venda entre a Câmara e os moradores. Vamos aos artigos:

Art. 17 - À Câmara compete conceder terras para aforamentos, para edificar prédios urbanos [...] (grifo nosso)

Art. 18 - O que obtiver a concessão pagará cem réis por braça de frente e assim qualquer outra pessoa para quem passar o domínio, tanto por título de compra, como por sucessão, doação ou troca. (grifo nosso)

A organização do espaço, nesses artigos, se dá pela constituição dos sujeitos representados, de um lado, pelo poder público e, do outro, pelo futuro proprietário de terras que, interpelados em sujeitos, significam e são significados em seus sentidos sociais públicos urbanos (ORLANDI, 2001).

Pela linguagem desses artigos, o Código antecipa, pelo efeito da argumentação, as primeiras redes de sociabilidade dos agentes públicos e privados com a concessão de terras para edificação de prédios, ao instituir modalidades de comercialização das terras públicas da União através da Câmara. Essa relação comercial entre sujeitos da linguagem reverbera sentidos de que a enunciação do comércio de terras urbanas está tomada por outra enunciação já dita, já ouvida. Ou seja, "é impossível pensar a linguagem, o sentido, fora de uma relação. Nada se mostra a si mesmo na linguagem. Algo sozinho não é linguagem. Algo só é linguagem com outros elementos e nas suas relações com o sujeito" (GUIMARÃES, 1989, p.74). 
Em maio de 1874, a Assembleia Legislativa Provincial, através da lei n. ${ }^{\circ}$ 3, eleva a Vila de São Luiz do Paraguai à categoria de cidade com o nome de "São Luiz de Cáceres". Essa nomeação provoca ruptura da condição de vila para cidade, e vai institucionalizar o ordenamento da cidade em oposição à falta de planejamento, com a aprovação pela Câmara Municipal do primeiro Código de Posturas, em 1876, o qual, de acordo com o Capítulo $1^{\circ}$. "Demarcação e Embelezamento da Cidade", determina "o arruamento e nivelamento das ruas da cidade, praças e lugares que pelo seu desenvolvimento oferecem esperanças de [...] e futura edificação". No artigo $5^{\circ}$, o Código diz ainda sobre "a nova denominação às ruas e praças e a respectiva numeração aos edifícios públicos e particulares". Ou seja, institucionalmente, o código projeta uma mudança política e administrativa para a cidade. E como legislação “classifica e coleciona os territórios urbanos, conferindo significados e gerando noções de civilidade e cidadania diretamente correspondentes ao modo de vida" (ROLNIK, 1997, p. 13) da população.

O nome "São Luiz de Cáceres" é duplamente marcado pelo memorável do nome do Governador Albuquerque, e se constituiu na enunciação que inclui marcas de outras enunciações que vão construindo o nome da cidade. Ao contrário de outros sintagmas que não predicam os nomes como em "Maria do Paraguay" e "São Luiz do Paraguay", em "São Luiz de Cáceres", o sintagma "de Cáceres” estabelece uma relação de pertencimento recíproco, "São Luiz" determina "Cáceres" à medida que "Cáceres" determina "São Luiz", ou seja, os nomes rememoram a enunciação inicial que deu nome ao Governador. Como vimos no recorte do documento do capelão, "São Luiz" é um nome dado à Igreja da Vila em homenagem ao Governador.

Em 1938, o município de São Luiz de Cáceres passa a denominar-se Cáceres, através do decreto-lei estadual $n^{\circ}$. 208, de 26 de outubro de 1938. Essa renomeação, a segunda na condição de cidade, foi dada do lugar do interventor federal em Mato Grosso, Julio Muller, nomeado pelo governo Vargas.

Dez anos mais tarde, o Prefeito Municipal de Cáceres sanciona o Código de Posturas Municipais que, através da Lei $n^{\circ}$. 5/1948, prevê, no artigo $1^{\circ}$. do Capítulo I "Divisão e Organização", a divisão da cidade em duas zonas: urbana ou central e suburbana ou agrícola. Esse código regulamenta obras e construções com vistas ao funcionamento da cidade que, tendo nascido nos limites de um "projecto da boa 
polícia", se estende, transpondo os espaços demarcados em direção ao rural, num movimento de sentidos oposto ao da criação da vila que se funda no rural (um sítio).

Ou seja, o código define e separa o espaço central/urbano do espaço suburbano e agrícola, significando o distanciamento entre sujeitos no mesmo território da cidade.

No apagar das luzes do século XX, a Lei no . 9, de 21/12/1995, institui-se o Plano Diretor do Município de Cáceres, compreendendo os Códigos Sanitário, Tributário e de Obras", "visando a instrumentalizar o planejamento e o desenvolvimento da cidade para cumprir a função social da propriedade ${ }^{12}$."

\section{Palavras Finais}

Retomando o objetivo deste artigo, o nome dado ao povoado na ata de fundação e outros nomes que se seguiram até a constituição da cidade de Cáceres "envolve lugares de dizer diferentes, o que diz respeito ao fato de que uma enunciação que nomeia, pode estar citando nomeações diversas" (GUIMARÃES, 2005, p. 37).

Independentemente da situação política do Brasil-colônia, vice-reino, reino, República e Estado Novo, os sentidos lusitanos na nomeação/renomeação da cidade de Cáceres se estabelecem, apagando os sentidos do sintagma "do Paraguai", que faz referência ao rio que banha a cidade de Cáceres.

Em relação à legislação, exceto a ata de fundação que institui um planejamento urbano para a vila, os Códigos de Postura $(1860,1876,1948)$ funcionam como o interpretável do que se diz em relação a um passado de enunciações em que os nomes foram se dando. Desse modo, os códigos planejam a espacialidade da cidade sobre o que está sendo dito/nomeado e, por sua vez, estabelecem juridicamente relação de deveres para o sujeito que vive na cidade e na zona rural.

Os nomes dados à vila e à cidade, na ordem que seguem - Villa Maria do Paraguay; Freguesia de São Luiz de Vila Maria; Vila de São Luiz do Paraguai; São Luiz de Cáceres (cidade) e Cáceres (cidade), no período da colonização até o Estado Novo, movimentam sentidos por uma memória lusitana e local, e, nessa sequência, os sentidos do nome do Governador se estabelecem no atual nome da cidade - Cáceres constituindo o enunciável, o dizível, mesmo que os sujeitos instituídos na linguagem desses documentos possam divergir desses sentidos.

\footnotetext{
${ }^{12}$ Cf. o artigo $1^{\circ}$ do Código.
} 


\section{Referências Bibliográficas}

ARAUJO, Renata Malcher de. Coimbra, Albuquerque e Vila Maria: A Guarda do Paraguai. In: A Urbanização do Mato Grosso: discurso e método. Tese de Doutorado. Universidade Nova de Lisboa, 2001.

A urbanização da Amazónia e do Mato Grosso no século XVIII, povoações civis, decorosas e úteis para o bem comum da coroa e dos povos". Disponível em: http://www.scielo.br/scielo.php?pid=S0101-7142012000100003\&script=sci_arttext.

Acesso em: 10/12/2013.

BERGER, John. Modos de ver. Tradução Lúcia Olinto. Rio de Janeiro: Rocco, 1999.

CORBALAN Kleber Roberto Lopes. Igreja Católica na Cuiabá Colonial: da primeira Capela à chegada do primeiro Bispo (1722 - 1808). Dissertação de mestrado, PPGHis, UFMT, 2006. Disponível em: https://www.google.com.br/search?q=CORBALAN+ Klber+Roberto+Lopes.+Igreja+Católicca+na+Cuiabá+Colonial\%3A+da+primeira+Cap ela+à+chegada+do+primeiro+Bispo+(1722+-808\&oq 808\&oq Acesso em: 10/03/2014.

DERNDT, Maria Fernanda. Método e Arte: criação urbana e organização territorial na capitania de São Paulo 1765-1811. Tese de Doutorado. Faculdade de Arquitetura e Urbanismo da USP, 2010.

FLEXOR, Maria Helena Ochi. Núcleos urbanos planejados do século XVIII. In: Rua, Salvador-BA, 1988, 1 (1), p. 89-114.

FLORENCE, Hercules. Viagem fluvial do Tietê ao Amazonas. Autor [texto introdutório] e tradução Visconde de Taunay; prefácio de Mario Guimarães Ferri. SP: Cultrix, Editora da USP, 1977.

FREYRE, Gilberto. Contribuição para uma sociologia da biografia. Edição da Fundação Cultural de Mato Grosso (Em comemoração ao bicentenário de fundação das cidades de Corumbá e Cáceres), 1978.

GUIMARÃES, Eduardo. Enunciação e história. In: História e sentido na linguagem. (Org.). Campinas, SP: Pontes, 1989.

. Texto e argumentação: um estudo de conjunções do português. 3. ed. Campinas, SP: Pontes, 2002.

Os limites do sentido: um estudo histórico e enunciativo da linguagem. 3. ed. Campinas, SP: Pontes, 2005a.

Semântica do Acontecimento. 2. ed. Campinas, SP: Pontes, 2005b.

- Domínio semântico de determinação. In: MOLLICA, Maria Cecília e GUIMARÃES, Eduardo. (Orgs.). A palavra: forma e sentido. Campinas: Pontes Editores, RG Editores, 2007.

2011.

Análise de Texto. Procedimentos, Análise, Ensino. Campinas, Editora RG,

Em torno do nome próprio de cidade sobre a produção dos sentidos de uma

origem. In: Cadernos de Estudos Linguísticos. Unicamp. IEL, Campinas: SP, $\mathrm{n}^{\mathrm{o}}$ 53(2), Jul/Dez 2011. 
KEHDI, Valter. Formação de palavras em português. 4. ed. São Paulo: Ática, 2007.

MENDES, Natalino Ferreira. História de Cáceres: história da administração municipal. 2. ed. Revisão atualizada. Cáceres-MT: Editora UNEMAT, 2009.

ORLANDI, Eni. Interpretação; autoria, leitura e efeitos de trabalho simbólico. Petrópolis, RJ: Vozes, 1996.

A fundação de um Estado: cidade de São Salvador, Brasil. In: Cadernos de Estudos Linguísticos. Unicamp. IEL, Campinas: SP, nº 53(2), Jul/Dez 2011.

PAYER, Maria Onice. O rural no espaço público urbano. In: ORLANDI, Eni P. (Org.).

A cidade atravessada - Os sentidos públicos no espaço urbano. Campinas: Pontes, 2001.

ROLNIK, Raquel. A cidade e a lei: legislação, política urbana e territórios na cidade de São Paulo. São Paulo: Studio Nobel-FAPESP, 1997. (Coleção cidade aberta) O que é cidade? São Paulo: Brasiliense, 2004.

ZATTAR, Neuza. As calçadas: espaços públicos ou privados? In: Línguas e Instrumentos Linguísticos. Ed. 23/245, jan./jun.; jul./dez, Campinas: IEL, 201

Documentos:

Código de Postura da Câmara Municipal de Villa Maria, 1860.

Código de Postura da Câmara Municipal da cidade de São Luiz de Cáceres, 1876.

Código de Posturas Municipais, Lei nº 5, de 8 de março de 1948.

Lei Complementar $n^{\circ} 19$, de 21/12/1995, que cria o Plano Diretor do Município de Cáceres. 
Para citar essa obra:

ZATTAR, N. Cáceres - nome luso de cidade mato-grossense. In: RUA [online]. $\mathrm{n}^{\circ} .21$. Volume 1, p. 155 - 170 - ISSN 1413-2109. Junho/2015. Consultada no Portal Labeurb Revista do Laboratório de Estudos Urbanos do Núcleo de Desenvolvimento da Criatividade.

http://www.labeurb.unicamp.br/rua/

Capa: colecao-imagens-periodo-colonial-mato-grosso/678/ Disponível em:

http://www.sudoestesp.com.br/file/

Laboratório de Estudos Urbanos - LABEURB

Núcleo de Desenvolvimento da Criatividade - NUDECRI

Universidade Estadual de Campinas - UNICAMP

http://www.labeurb.unicamp.br/

Endereço:

LABEURB - LABORATÓRIO DE ESTUDOS URBANOS

UNICAMP/COCEN / NUDECRI

CAIXA POSTAL 6166

Campinas/SP - Brasil

CEP 13083-892

Fone/ Fax: (19) 3521-7900

Contato: http://www.labeurb.unicamp.br/contato 